\title{
NO CENTRO DO PROCESSO DE PALAVRAS
}

\section{IN THE CENTER OF THE WORDS PROCESS}

Maria Dayane Pereira ${ }^{1}$

\section{RESUMO}

Este ensaio esboça o lento e atemporal momento das vertigens, ânsias, dores, alegrias metamorfósicas sentidas pelo corpo em crise de encontro-confronto a procura dos arranjos de uma pesquisa - ao nível de mestrado - desde as capoeiras, desde educação, desde corpo, desde mulher. Trata-se de uma abordagem qualitativa do momento mesmo em que se vive a cerimônia de iniciação para compor pensamentos de pesquisa, de produção escrita na e para a academia. Assume-se a escrita como prática social e conforme fazemos, pode ou não constituir-se um processo que adentra os campos de tensão da sociedade, provocando incômodos, inquietações e reflexões sobre tantas questões.

Palavras-chaves: Escrita; Corpo; Academia.

\section{ABSTRACT}

This essay outlines the slow and timeless moment of the vertigo, cravings, pains, metamorphic joys felt by the body in crisis of encounter-confrontation the search for the arrangements of a research - at masters level - since capoeiras, since education, since body, since woman. This is a qualitative approach from the moment the initiation ceremony is lived to compose thoughts of research, of written production in and for the academy. Writing is assumed to be a social practice and, as we do, it may or may not constitute a process that enters the tension fields of society, causing discomfort, concerns and reflections on so many issues.

Keywords: Writing; Body; Academy.

\section{QUANDO EFETUAR A ESCRITA É AFERTASSE A SE PRÓPRIA}

As possibilidades de apresentação, a composição dos arranjos de um estudo, a ordem em que eles se encontram dispostos - se ocupam poros, brechas ou rodapés - no corpo do texto, é resultado das sensações, experimentações no pesquisar e dos riscos assumidos no

\footnotetext{
${ }^{1}$ Mestranda em Educação Contemporânea - PPGEduc (UFPE-CAA). Graduada em Licenciatura em Pedagogia pela Universidade Federal do Piauí, UFPI. e-mail: dayanemdp93@gmail.com.
} 
(des)organizar das ideias. Os riscos que aqui se assume "[...] é o do ato de falar com todas as implicações” (LÉLIA GONZALEZ, 1983, p.225). Nesse sentido, é que se pretendia mover na escrita de uma dissertação de mestrado, desde educação, capoeira(s) e o que chamo de colonialidade do corpo da mulher.

Parece-me certo: vivo a cerimônia de iniciação para compor pensamentos de pesquisa, de produção escrita na e para a academia. Apanho livros, blocos de notas, canetas, lápis, algumas folhas de papel, a imaginar que ao entardecer já teria o gosto de ver páginas por inteiras escritas. Precipitei-me e fui feliz no momento errado. E no já, enquanto tenho que esperar as próximas palavras para formar uma frase... peguei a mim mesma imaginando uma menina no auge dos seus seis anos altivos e bem vividos, em seu poder um graveto, assumindo o risco e a dignidade de rabiscar na terra quente, letra por letra, Amanda de Antônia de José de Manuel do leite, neta de Toinha rezadeira, seu nome geracional por inteiro.

A imaginação não é muito companheira dos prazos acadêmicos. Mato a menina dentro de mim. E na hora do crepúsculo, estava, no parafrasear de Roland Barthes (2004), no centro do processo de palavra, efetuando a escrita e afetando a si própria. E eis que em letras garrafais na folha tinha escrito: introdução. Nada mais.

Busco meios para me aproximar de narrativas: forço a vista flanando livros, tateando anotações, junto frases imprecisas e ultimamente dei para retornar a caverna ancestral onde desenhei bisões flechados e sangrando para garantir uma boa caça. $\mathrm{O}$ ato de escrita produzia efeitos mágicos no mundo, o verbo não era uma imitação dele no texto. É compreensível nos perdermos nas formas embrionárias da escrita quando se está na lida com as palavras. E existem muitas palavras.

Penso quieta e sentada: como faço agora? A experiência de "mexer", "modelar" começos (embora o que escrevo não tenha começo, é uma continuação), fazer surgir da matéria-palavra formas ao olhar, traduz o envolvimento do corpo todo em gestos de agregar a essa, pensamentos, sentidos, sentimentos, em movimentos de ações acolhedoras e complexas, inauguradas ao alisar, emendar, enrolar, esticar, amassar letras em palavras, e daí dar forma a 
frases, que se amolduram em sentidos mais do que palavras e frases. Escrever é uma magia muito forte, não sei se estou preparada para ela.

Lentamente, ru, rum, rumina-se as pré-posições sobre o que seria um bom (entre aspas) começo de estudo. Como prestar-me a descrever, daqui do teclado, os arranjos de uma escrita que não fala sobre uma pesquisa, mas já é a própria pesquisa em obra, falando ela mesma na processualidade em ato? Com uma pergunta e nenhuma instrução, abrem-se as possibilidades de vários caminhos, inclusive o do beco sem saída. Há o risco - e talvez nem dê em terras novas (novas como possibilidades de um olhar que transcende o olho).

Antes que passem muitas páginas, é preciso não esquecer de argumentar sobre a necessidade do esforço para um uso inclusivo da linguagem. A ideia dessa reflexão não se espraia nas problematizações sobre a decodificação e/ou re-tradução da linguagem científica até a fala comum. Isso é, nas posições que sustentam ou refutam que a singularidade da linguagem científica deveria desaparecer quase que por completo até tornar-se acessível a maioria da população. Sousa Santos (1989) faz uma defesa a tal procedimento.

Bem distante disso, trata-se apenas de assumir que a linguagem como parte da prática social, se mostra muito mais do que palavras escritas, pronunciadas e escutadas, seu uso tanto pode estabelecer e sustentar relações de dominação quanto, de maneira contrária, pode contestar, denunciar e fazer com que tais problemas sejam superados. É responsabilidade social da/o pesquisadora/o oferecer uma linguagem com a qual se pode questionar e transgredir binarismos e assimetrias.

Usar palavras, exige mover-se com cuidado, para que elas não atropelem realidades, reforcem preconceitos, binarismos, sexismos, esteriótipos de gênero. Acompanhe-me: estou pintando uma seta que aponta para as armadilhas da língua corrente. Pescando nas entrelinhas das palavras de bell hooks² (2013), a linguagem, a depender da maneira como é usada, pode ser um instrumento para colonizar, um território que limita e define, criando mais contextos

${ }^{2}$ bell hooks é o pseudônimo de Gloria Jean Watkins. O nome é grafado com letras minúsculas pela própria autora. 
de poder em vez de compartilhamento nas diferenças, tornando-se uma barreira para construção de uma educação enquanto prática transgressora.

Acredito que tal preocupação contribui para a construção de um estilo de escrita em que coexistem as diferenças, a que Glória Anzaldúa (2005) ${ }^{3}$ denomina de escrita mestiza, isso é, uma escrita construída da mistura de diferentes gêneros textuais que em diálogo rompe com as dicotomias: masculino e feminino; heterossexual e homossexual; branco e de cor; razão e emoção; mítico e real; espírito e matéria; mente e corpo; oralidade e escrita, o eu e o outro.

É essa linguagem, de caráter híbrido, que permite assentar e visualizar os espaços de fronteiras, os entrelugares, encruzilhadas, espaços de múltiplas identidades e vozes (SANDRA AZERÊDO, 2011). Neste ponto, é valido mencionar que, as "metodologias e epistemologias feministas" (MARTHA CASTAÑEDA 2008; SANDRA HARDING 1999; MARGARETH RAGO 1998; RHODA LINTON 1997), têm buscado escrever numa linguagem que possibilite aos grupos silenciados, destaco as mulheres (nós), falarem a partir de sua própria língua. Gayatri Spivak (2010) é uma das autoras que faz reflexões importantes sobre a (im)possibilidade de fala da/do subalternizada/o.

Essas são linhas que anunciam uma defesa, uma justificativa, um ato de resistência, uma advertência, mais que também podem tornar-se uma atitude de (re)conciliação entre a rigidez da universidade que demanda um modo de argumentação, em que a distância entre objeto de estudo e pesquisador/a torna-se uma condição sem a qual inexistiria um discurso cientifico. Essa condição que permite com que alguns sujeitos (se sabe na maioria quem os são) pertençam a roda de pesquisadores, cientistas e professores, encarcera o discurso acadêmico em uma moldura, em uma aspereza explicativa preenchida por estilhaços gramaticais, lexicais, um estilo fechado a vivacidade, a espontaneidade, sem relação com um "contar história" e intrigado com as narrativas de caráter vivo da experiência vivida sobre a qual se constroem um discurso.

\footnotetext{
${ }^{3}$ Sobre o caminho para uma escrita mestiça, pode se está vendo também: Glória Anzaldúa. Toward a Mestiza Rhetoric: Glória Anzaldúa on Composition and Postcoloniality. In: OLSON, Gary A; WORSHAM, Lynn. Race, Rhetoric, and the Postcoloniality. New York: State University of New York, 1999. p. 43-78.
} 
Desse modo, é que se afirma que essa não se constitui em uma escrita sentada (não se escreve apenas sentada/sentado), mas uma escrita redondamente movente, transpirada, sem véu de qualquer cor, golpeada por forças atrituosas que jogam letras dançantes desenhadas não apenas por dedos ainda não cansados, mais também por corpos vibrantes, transbordantes, corpos sem "saia", corpos "fiquem", que borram contornos, apagam modelos, sem modelos, contra modelos, sem contrário, mas que contrariam (re)existindo.

Assim, quando em pretensão de construir um estudo de dissertação acerca de como os saberes ancestrais ensinados na roda de capoeira contribuem para o enfrentamento da colonialidade do corpo da mulher, buscarei fazer desde - desde capoeira(s), desde ancestralidade, desde educação, desde mulher, desde corpo - "um corpo complexo, contraditório, estruturante, estruturado", sem fronteiras fixas, e não a partir de uma linguagem sobre e de uma "[...] visão de cima, de lugar nenhum", como coloca Donna Harawayem “saberes localizados" (1995, p. 30).

Essa proposta provoca em mim sensações mistas de entusiasmos e medo, pois o

processo de realizá-la exige a lida com as palavras no corpo-a-corpo comigo mesma. Corpopesquisadora, real, em (con)vivências, (in)definido, que escreve e se inscreve na escrita, enquanto elemento de comunicação com o contexto de pesquisa, a roda de capoeira não sendo capoerista. E esse é um processo que tortuosamente e prazerosamente ainda se faz, no momento mesmo que me acontece, as forças vivas desdobradas pelo corpo na escrita da agonia do problema, das questões (surgirão? Existirão?) e do campo problemático de produção.

\section{ESCREVO O QUE ACONTECE AGORA}

Agora, estou sentada, longe de uma escrivaninha e de um quarto todo meu, "esquentando o corpo para iniciar, esfregando as mãos uma na outra para ter coragem" (CLARICE LISPECTOR, 1999, p. 14), isso depois de ter-me bamboleado, bloqueado, enrijecido, amolecido, umedecido, deslizado, feito mistura da terra seca com a água, juntas, 


\section{novitato \\ Debates Insubmissos}

formando o barro que se manifesta em mãos modeladoras. Devaneios à nordestina de um corpo em encontro com a capoeira(s) e a materialidade do barro do Agreste pernambucano ${ }^{4}$.

Precisei de tempo para perceber que, embora muita coisa tenha acontecido para que isso acontecesse, foi na emergência e intensidade desse encontro que visualizei possiblidades de começar. Em lampejos de memórias torno a (re)lembrar o escrito por Yannick Butel (2013, p. 201): “[...] há encontros na vida que podem parecer ocasionais e nos quais algo da vida está em jogo". Assim, ex-pondo-me à capoeira(s), ao barro em Agreste, escapo da rotina domesticada de [não] me ser... pausa. Essa última frase me impressiona, constrange, não me sinto bem, meus órgãos esfriam, por isso, ao invés de ponto final encerro-a com reticências. Isso, não perceber-se corpo, se dá pela imposição do sistema moderno colonial/colonialidade de corpo? Como isso é possível, acaso não somos corpo desde que existimos? Negar o corpo pode nos ser fatal!

Estou procurando, estou tentando entender os motivos dessa minha desorganização profunda. Cúbitos, palmos, jardas, polegadas, passos, braças, não sei qual é a minha própria medida. Já estava por algum tempo em momentos de recuo in-produtivos - qualquer tentativa minha de inaugurar pensamentos se esbarrava na testa - não tinha sequer garranchos escritos, arranjos de questionamentos para a pergunta motriz. Procurava arrumar depressa uma maneira de me achar, enquanto era tempo, enquanto não entardece para os prazos acadêmicos.

Em horas sem relógio que ainda estão em mim (BACHELARD, 2009), em excesso de desaceleração, adio, apago, paro de escrever. O barro encontrado seca. Coloco água outra vez. Surgi a mão deslizando-o, massageando-o, conduzindo caminhos junto a água, o faz metamorfose, "o barro toma a forma que você quiser, você nem sabe estar fazendo apenas o que o barro quer" (LEMINSKI, 1983, p.90). Os corpos capoeiras também buscam a terra em cosmovisões ancestrais. Poderia uma mulher em capoeira desafiar e construir outras gravidades fora do chão - de pernas, braços, corpo inteiro para o ar?

\footnotetext{
${ }^{4}$ Em Caruaru, cidade localizada no Agreste do Estado de Pernambuco - PE, a arte no barro é uma tradição cultural, com significado econômico e simbólico para a região. Originária no Alto do Moura, onde viveu Mestre Vitalino, pela multiplicidades de artistas e obras produzidas, atualmente, é um dos maiores Centros de Artes Figurativas das Américas.
} 
Nessa mistura da terra com a água, tomo o barro (com o qual me encontrei) como metáfora do tornar-se/devir (DELEUZE; GUATTARI, 1997) do meu próprio corpo no processo de "sentipensar", a discussão dos limites, das (des)legitimidades impostas pela colonialidade do corpo sobre a mulher, tensionando: os corpos das mulheres capoeiristas desde os movimentos em roda, quando se deslocam pondo-se próximas ou fora do alcance de outrens. Posso não ter sentido o instante de quando efetuar a escrita é também afetar-se se própria.

Finalmente, seguro a caneta, sem medo do nível de nudez que possa vir a ser revelado, expulso um pouco de tinta vermelha de dentro e em quase sobressaltos de concentração para o ato de concatenar a escrita, interrupção. Encrenca de "colonialidade de gênero" (MARIA LUGONES, 2008) rabisca neste papel, vozes angustiadas vindas de outro lugar, que não era qualquer lugar, era o lugar de refúgio para os meus pés quando empoeirados, caem e tecem palavras sobre a superfície vertiginosa de um papel que começara a ser tateado por letras encrencadas, cuspida na calçada da domesticidade, embaralhada nas interações cotidianas: entre texto, corpo e contexto - texterritorialidade.

Pausa - transpiração, expiração, inspiração, recordações - (re)vivo um corpo que falta. Des/in/corporada em antigos ângulos vacilantes de (in)definições, arrastada em distintas direções pelas demandas cotidianas, o íntimo de si mesma e o tornar-se pesquisadora. Sem um corpo inteiro, tecidos por completo vivos, torno alquimia, distraída a perguntar-se: pesquiso ou persigo uma pesquisa? Corpovivênciase escrita em sopros e suspiros preliminares, se fundem, coabitam, transitam inseparáveis. Assim, retorno ao germinal, ao primário, ao barro, agindo e construindo como artista-artesã formas na matéria da argila para (re)significar o corpo.... [os cincos pontos dizem do lento e atemporal momento das vertigens, ânsias, dores, alegrias metamorfósicas sentidas pelo corpo] em crise de encontro-confronto a procura dos

\footnotetext{
${ }^{5}$ O sociólogo colômbiano Orlando Fals Borda ousa a criação de uma Sociologia sentipensante para a América Latina. Uma pessoa "[...] Sentipensante es el que combina larazón y el amor, El cuerpo y elcorazón, para deshacerse de todas las mal formaciones que descuartizan la armonía" (MONCAYO, 2009, p.12). O sentipensante não necessariamente é uma capacidade individual, do contrário se define no e para o coletivo.
} 


\section{Revista (O) \\ Debates Insubmissos}

arranjos des-arranjados de uma pesquisa desde as capoeiras, desde educação, desde corpo, desde mulher.

Agora, vou apagar a luz e dormir. Frases que beiram o quase não sentido é minha grande liberdade - tomei parte em não fazer ciência triste. Explico-lhe: precisei de uma pausa para retomar o fôlego e não perder o ânimo. Pronto! Agora vou dizer coisas sérias, prestem atenção: descolonizar o conhecimento e a escrita passa, ao entender com apoio em Paula Meneses (2016), por uma renegociação, revisão crítica de conceitos centrais, realizado de tal maneira que possa desafiar o privilégio epistêmico do Norte global e abrir espaços/tempos para a legitimidade de outros saberes e narrativas das múltiplas vozes.

Nessa direção, aqui, nesta escrita, assumi, por exemplo, que a roda de capoeira, insinua cotidianos praticados de produção de novas epistémes, as quais apresentam de modo passível de problematizar, categorias como raça-classe-corpo-gênero-educação para novamente criar contextos de problematização e complexidades, que situam o movimento de novas práticas educativas e de formação de sujeitos na perspectiva do ensinar-aprender em roda.

Pôr-se ao avesso, deslocar o eixo das discussões para o outro lado do mesmo plano, longe de uma epistemologia da verdade, contribui (acredito) para a construção de uma escrita mais saudável, honesta e qualitativa. Assim, pauta-se o debate propondo um rompimento com as narrativas dominantes que quando não deslegitima em totalidade, reduz a compêndios os saberes, à exemplos, das/dos capoeiristas, das mulheres do terreiro, das rezadeiras, dos movimentos sociais, lideranças comunitárias, movimentos estéticos-musicais de juventude, enfim. Insisto, à luz de Sousa Santos (2008) que é a partir das margens, das fronteiras, dos entrelugares que se pode ver com mais visibilidade as estruturas de poder e saber.

Dito isso, volto para o desejo de enfatizar que não só os ocidentais compreendem o mundo - não deu mais para adiar o momento de dizer o obvio. Se nos despirmos das lentes da colonialidade veremos que diferentes culturas, à exemplo, me aproximo das africanas em que nas manifestações enraizadas nas tradições orais (como é o caso da capoeira/s), comumente, há a relação integral entre pessoa e natureza, assim, seus corpos não são individualizados e 
separados, tornando-se assim o instrumento de construção e comunicação de conhecimentos, espaço de memória, imaginação e criação.

Nessa "gramática" desde corpo africano, um bom exemplo pode ser encontrado nos povos de etnia Himba na Namíbia que dão sentido para a sua existência através do corpo, comunicando experiências profundas e legítimas com todo cosmo. Ou seja, a comunicação e criação de significados comunitários se dão desde corpo. Nessa "gramática" desde corpo como uma visão, as mulheres cobrem-no com um creme que chamam de otjize, composto de gordura animal, ocre esfarelado e argila avermelhada, às vezes perfumada com resina aromática e, enfeitam-o com vários adereços. Assim, elas o convertem no meio e na finalidade de uma visão. Transformam a si mesma, convertendo corpos individuais em coletivo, plenamente inseridos no cosmo da comunidade. É assim que em "Corpos que nos possui: corporeidade e suas conexões", Anderson Tibau e Tania Dauster (2018) evidência algumas práticas corporais ancestrais dessa comunidade, focalizando, as práticas e representações entre as mulheres himbas.

Hoje, se está na onda do corpo - o século vinte inventou teoricamente o corpo - se divulga nos meios de comunicação de massa um/uma modelo de "corpo perfeito", (é o que se exclama, oh!), a indústria da beleza lança a cada verão um corpo esteticamente belo, (suspirase, ah! Espelho, espelho meu...), lotam-se as academias, as clínicas de cirurgias plásticasestéticas e, depois da mama, do peitoral masculino e dos glúteos, quero colocar silicone na panturrilha (é a fala da vez) e, olha as selfies (se diz sixxxx). Poucas pessoas conseguem falar mais do que isso em relação ao corpo - ele ainda é esse que desconhecemos, uma epistemologia a ser desvendada.

Vamos entrar devagar no assunto, pois a muito o corpo vive de fora. Convenhamos, pode ter sido uma entrada constrangedora. E agora, que se achava quase no fim destas linhas escritas, se sente a necessidade de perguntar: qual o lugar do corpo na educação? Preparandome para dar uma resposta e assim mover-se no texto, encontro em Márcia Strazzacappa (2011, p.79) a afirmação de que “[...] toda educação é educação do corpo”, pois as pessoas agem no mundo desde e através do corpo, ou melhor, por meio dos (não) movimentos do seu próprio corpo. 
É o movimento corporal, aponta a autora, que nos possibilita, comunicar, trabalhar, aprender, ensinar, sentir e sermos sentidas/os. E toda essa corporalidade parece estar ligada a duas distintas formas de educação, a saber: uma que estimula que o corpo fale, movimente-se, e outra que educa para o não-movimento, "para a repressão". De uma maneira, ou de outra, estamos sempre educando o nosso corpo. Nas palavras da autora, “[...] em ambas as situações, a educação do corpo está acontecendo. O que diferencia uma atitude da outra é o tipo de indivíduo que estaremos formando" (MÁRCIA STRAZZACAPPA, 2011, p.79).

Assim e, compreendendo que são multifacetadas e distintas as formas de pensar e se relacionar com o corpo na história, para explicitar da semântica que ele assume neste estudo, nota-o em seus diversos atravessamentos de influência social, cultural, econômica, política e científica. Nesse sentido, ao percebê-lo inserido dentro de um determinado contexto histórico e cultural significa não encerrá-lo aos limites da pele, mas reconhecê-lo além da condição biológica, orgânica e fisiológica. O que aqui chamarei de Colonialidade do corpo (discutida no espaço específico da América Latina) passa por essa compreensão.

Ou seja, discute-se a imposição do sistema moderno/colonial do corpo, não como uma abstração das experiências vividas - criar conceitos não é uma mera passividade diante do mundo, é uma intervenção, uma ressignificação, um reaprendizado dele - por isso, o proponho como uma aventura para revolução do sentir, capaz de reagir às opiniões generalizadas sobre o vivido. Ressalto, propor-se-á acrescentar o conceito de colonialidade do corpo às formas de colonialidade, do ser, do poder, do saber, de gênero e da natureza. Uma vez que se parte da compreensão de que não é possível estabelecer essas outras colonialidades se não desde corpo - elas não podem existir sem que essa exista.

Apenas um parêntese de observação conceitual: a colonialidade é a representação de que os padrões de poder fundados pela dominação colonial, sem exagero, nas mais diversas esferas da vida social, ainda não foram superados, obstante o colonialismo político formal tenha sido eliminado, assim, segue viva, perpetuada pelo apagamento de crenças, saberes, produções culturais, expressões, enfim, via universalização de práticas e conceitos. A existência da modernidade está ligada à colonialidade, não podendo existir sem ela. Autores 


\section{Revista

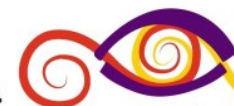 \\ Debates Insubmissos}

como, Aníbal Quijaro (1992), Walter Mignolo (2006), Sousa Santos (2008), Maria Paula Meneses (2014) se posicionam nesse sentido. Fecha parêntese.

Me enganei ao fechar o parágrafo. Conquanto, que é que se há de fazer? Errar é humano, me dou o luxo de [entre]abrir outro. Preciso trazer Maldonado Torres (2007) para escrever que a colonialidade resultado do colonialismo não é simploriamente uma relação colonial entre a cultura ocidental e outras culturas, isso é, entre uma nação e outra, mas sim padrões simbólicos, de comportamentos, crenças, valores, intersubjetividades, imaginários que existem em consequência de uma situação colonial pré-existente. Enfím, é a representação de que a estrutura de pensamento colonial se mantém nas obscuridades da modernidade.

Aproveito o arrepio - estou ouvindo uma música batucada que vem de alguma casa vizinha - e trago [ou seria ensaio?] uma conversação que harmoniza proposições acerca da inventividade, do processo em criação no qual me lanço e lanço como uma visão sentipensada desde o Sul - a invenção do conceito de Colonialidade do Corpo. Está nascendo, percebe? Já vi uma cena de uma elefanta parindo! Quanta delicadeza em tão grossas patas. Evidente que, nessa gestação inventiva, a maternidade/paternidade é múltipla (não sei quem é o pai e mãe), a fecundação será construída desde as contranarrativas,dos estudos pós-coloniais, das "epistemologias do sul" (SOUSA SANTOS, 2010), dos campos de estudos das epistemologias feministas, inspirada nos conceitos de "colonialidade de gênero" (MARIA LUGONES, 2008), “colonialidade do ser" (MALDONADO-TORRES, 2007), "do saber" (WALTER MIGNOLO, 2003), “do poder” (QUIJANO, 2005) e "da natureza” (CATHERINE WALSH, 2007) - o que se sabe é que mais adiante rebentará.

Nesse jogo de corpo, recebo as circunstâncias e escrevo com elas. Cada vez mais sou convocada ao "Paraná ê!/Paraná ê,/Paraná!" [leiam cantando] da capoeiragem como possibilidade de vontade de potência para a emancipação do corpo da mulher. Dessa maneira, considerando que na capoeira o corpo pensa em movimentos soltos, diversos, por vezes improvisados, se pergunta que as mulheres possam transformar seus próprios corpos em

${ }^{6}$ Cantiga de Capoeira. Domínio Público. Disponível em:https://www.letras.com.br/capoeira/parana-e-parana-eparana. 
contradiscursos na divisão social dos papeis do corpo imposta pela visão hegemônica masculina e misógina.

Sentiu? Escrever tem dessas coisas: de vez em quando variam-se as maneiras, não se constrói de um fôlego só. Conforme fazemos, pode constitui-se um processo que adentra os campos de tensão da sociedade, provocando incômodos, inquietações e reflexões sobre tantas questões. Interrompo agora para responder a um instante meu: um cafezinho.

\section{REFERÊNCIAS}

AZERÊDO, Sandra. Preconceito contra a mulher: diferença, poemas e corpos. 2. ed. São Paulo: Cortez, 2011.

ANZALDÚA, Gloria. Borderlands/La Frontera. The New Mestiza, San Francisco, Estados Unidos, Spinters/Aunt Lee, 2005.

BACHELARD, Gaston. A poética do devaneio. São Paulo: Martins Fontes, 2009.

BUTEL, Yannick. A arte do encontro, uma arte da distância: de Thomas Richards e Mario Biagini a Jerzy Grotowski. In: Rev. Bras. Est. Pres. Porto Alegre, v. 3, n. 1, Jan./abr. p. 198219, 2013. Disponível em: http://www.seer.ufrgs.br/presenca. Acesso em: 22 de dez. 2018.

CASTAÑEDA, Martha Patricia Salgado. Metodología de La investigación feminista. Antigua Guatemala: Centro de Investigaciones Interdisciplinarias em Ciencias y Humanidades -CEIIHC- de La Universidad Nacional Autónoma de México - UNAM, 2008.

DELEUZE, Gilles; GUATTARI, Félix. Mil Platôs: capitalismo e esquizofrenia (Volume 4), Rio de Janeiro: Editora 34, 1997.

GONZALEZ, Lélia. Racismo e sexismo na Cultura Brasileira. In: Rev. Ciências Sociais Hoje, Brasília: ANPOCS, v. 2, p.223-244, 1983. Disponível em: $<$ http://www.goo.gl/VFdjdq $>$. Acesso em: 21 de maio. 2018.

HARDING, Sandra. Ciencia y Feminismo. Existe un método feminista?". In: Eli Bartra, Debates en torno a una metodología feminista? Ciencia y feminismo. Madrid: Ediciones Morata, 1999.

HARAWAY, Donna. Saberes localizados: a questão da ciência para o feminismo e o privilégio da perspectiva parcial. In: Cadernos Pagu, v.5, p. 07-42, 1995.

HOOKS, bell. Ensinando a transgredir: a educação como prática de liberdade. São Paulo: Martins Fontes, 2013. 
LEMINSKI, Paulo. Caprichos \& Relachos. São Paulo. Editora brasiliense, 1983.

LISPECTOR, Clarice. A Hora da Estrela. Rio de Janeiro: Rocco, 1999.

LINTON, Rhoda. Rumo a um Método Feminista de Pesquisa. In: Alison M. Jaggar e Susan Bordo (orgs). Gênero, Corpo, Conhecimento. Rio de Janeiro: Record/Rosa dos Tempos, 1997.

LUGONES, María. Colonialidade e gênero. Rev. Tabula Rasa. Bogotá, n.9, jul/dez. p.73$101,2008$.

MALDONADO-TORRES, Nelson. Sobre la colonialidaddel ser: contribuciones al desarrollo de un concepto. In: Santiago Castro-Gómez y Ramón Grosfoguel. El giro decolonial. Reflexiones para una diversidad epistémica más alládel capitalismo global. Bogotá: Iesco-Pensar-Siglo Del Hombre Editores,p. 127-167, 2007.

MENESES, Maria Paula. Diálogos de saberes, debates de poderes: possibilidades metodológicas para ampliar diálogos no Sul global. In: Em Aberto, V. 27, n. 91, p. 90-110, 2014.

MENESES, Maria Paula. Os sentidos da descolonização: uma análise a partir de moçambique. In: Catalão, v. 16, n. 1, jan./jun. p. 26-44, 2016.

MIGNOLO, Walter. Histórias locais/projetos globais: colonialidade, saberes subalternos e pensamento liminar. Belo Horizonte: UFMG, 2003.

MIGNOLO, Walter. Os esplendores e as misérias da "ciência": colonialidade, geopolítica do conhecimento e pluri-versalidade epistémica. In: Santos, B.V.S. Conhecimento prudente para uma vida decente: 'um discurso sobre as ciências' revisitado. 2. ed. São Paulo: Cortez, 2006.

MONCAYO, Víctor Manuel. Una sociologia sentipensante para América Latina: Orlando Fals Borda Antología. Bogotá: Siglo XXI Editores y CLACSO, 2009.

QUIJANO, Aníbal. Colonialidad y modernidad/racionalidade. In: Rev. Perú Indíg, v. 13, n. 29, p. 11-20. 1992. Disponível em:< https://www.ecumenico.org $>$. Acesso em: 12 de maio 2018.

QUIJANO, Aníbal. Colonialidaddel poder, eurocentrismo y América Latina. In: LANDER, E.(Org.). La colonialidaddel saber: eurocentrismo y ciências sociales. Perspectivas Latinoamericanas. Buenos Aires:Clacso, 2005. p. 227-27.

RAGO, Margaret. Epistemologia Feminista, Gênero e história. In: PEDRO, Joana M. e GROSSI, Mirian P. (orgs), Masculino, Feminino, plural. Florianópolis, Editora das Mulheres,1998, pp.24-42.

SOUSA SANTOS, Boaventura de. Introdução a uma ciência pós-moderna. Rio de Janeiro: Graal, 1989.

SOUSA SANTOS, Boaventura de. Para uma sociologia das ausências e uma sociologia das emergências. In: Revista Crítica de Ciências Sociais, v.63, n.2,p. 237-280, 2008. 
SOUSA SANTOS, Boaventura de. Para além do pensamento abissal: das linhas globais a uma ecologia dos saberes. In: Santos, B.V.S; Meneses, M.P. Epistemologias do sul. São Paulo: Cortez, 2010.

SPIVAK, Gayatri. Pode o subalterno falar? Belo Horizonte: editora UFFMG, 2010.

STRAZZACAPPA, Márcia. A educação e a fábrica de corpos: a dança na escola. In: Cadernos Cedes, ano 20, v. 53, n. 69, abril/, 2001.

TIBAU, Anderson; DAUSTER, Tania. Práticas e representações do corpo entre mulheres himba. In: NOVAES, Joana de Vilhena; VILHENA, Junia. O corpo que nos possui: corporeidade e suas conexões. Curitiba: Appris, 2018.

WALSH, Catherine. ¿Son posibles unas ciências sociales/culturales otras? Reflexiones en torno a las epistemologias decoloniales. In: Revista Nómada, n.26, Abril/, p. 102-113, 2007.

Submetido em: $23 / 07 / 2019$

Aprovado em: 10/08/2019 